\title{
Geochemical record and climatic implications during the last 2000 years from Lake Hurleg in northeastern Tibetan Plateau AI-YING CHENG ${ }^{1,2}$, JUN-QING YU ${ }^{1,2}$, CHUN- LIANG GAO $^{1,2}$, LI-SHA ZHANG ${ }^{1,2}$ \\ ${ }^{1}$ Key Laboratory of Comprehensive and Highly Efficient Utilization of Salt Lake Resources, Qinghai Institute of Salt Lakes, Chinese Academy of Sciences, Xining 810000, China; \\ ${ }^{2}$ Key Laboratory of Salt Lake Geology and Environment of Qinghai Province, Xining 810008, China; aycheng@isl.ac.cn
}

High-resolution climate proxy records covering the last two millennia on the Qinghai - Tibetan Plateau are scarce yet essential to evaluation of the patterns, synchroneity and spatial extent of past climatic changes. Therefore, paleoclimatic study of the Qinghai-Tibetan Plateau is especially fruitful for understanding the climate on hemispheric scales. Lake Hurleg mainly fed by the Bayin River is a freshwater lake located in the northeastern Qaidam Basin on the northeastern Tibetan Plateau. Changes of the lake level can be documented by the sedimentary record of the lake, which respond sensitively to the precipitationdominated catchment inflow of the Bayin River, because the lake is of hydrological closure with a suitable size and water chemistry.

The sedimentary environment of Lake Hurleg was reconstructed using data derived from two sediment cores with assured quality. The sediments of Hurleg Lake are tested by XRF core scanning with high-resolution, Grain size and X-Ray Powder Diffraction (XRD) combining with chronology $\left(\mathrm{AMS}^{14} \mathrm{C},{ }^{210} \mathrm{~Pb}\right.$ and $\left.{ }^{137} \mathrm{Cs}\right)$. Multivariate statistical analysis has been used to reveal associations between elements and deviations that can be environmentally significant. The results of principal component analysis of the element dataset indicate that the $\mathrm{K}, \mathrm{Ti}, \mathrm{Mn}$ in two cores reflects variations in detrital input via runoff. The element concentrations, together with grain size and XRD, clearly indicate distinct oscillations, which we interpret as changes in the environment of lake and its catchment ultimately driven by climate. Analysis of the precipitation change from nearby tree rings, reveals the Lake Hurleg is similar with the treering records. Over the past 2000 years the precipitation from the Hurleg Lake indicates that according to the results of the arid and semi-arid is the longest period. Furthermore during the last 2000 years reconstruction of the annual precipitation series also has the change of a cycle. 